Neurosurg Focus 7 (6):Article 3, 1999

\title{
Lumbosacral junction fixation and fusion after complete L-5 spondylectomy
}

\section{Case report}

\section{Paul W. Detwiler, M.S., M.D., Randall W. Porter, M.D., Neil R. Crawford, Ph.D., Paul J. Apostolides, M.D., and Curtis A. Dickman, M.D.}

Division of Neurological Surgery, Barrow Neurological Institute, St. Joseph's Hospital and Medical Center, Phoenix, Arizona

The goals of surgery for metastatic disease of the lumbosacral spine are to relieve compression of the thecal sac and nerve roots, to resect malignant tissue, and to create a stable reconstruction of the spine. Reconstruction of the lumbosacral junction, specifically the L-5 vertebral body, is particularly challenging because the biomechanical properties of this level differ from other areas of the spine.

A 40-year-old woman with intraductal breast carcinoma that metastasized to the L-5 vertebral body presented with progressive low-back pain, right-sided L-5 radiculopathy, and weakness. Magnetic resonance imaging revealed a pathological fracture of the L-5 vertebral body with compression of the cauda equina. The L-5 posterior arch, both facet joints and pedicles, and the posterior third of the vertebral body were removed via a posterior approach. A pedicle screw fixation system was applied from L-4 to S-1. The patient was repositioned, and a transabdominal approach was used to resect the anterior two thirds of the L-5 body, which was reconstructed using an allograft bone strut. An interference bone screw was placed through the inferior aspect of the allograft and screwed into the body of S-1 to provide stability for the reconstructive graft.

The patient's clinical recovery was excellent. She was ambulating without difficulty when seen at 19-month follow-up examination.

Complete spondylectomy by using this novel fusion technique was efficacious in the treatment of metastatic disease to the vertebral column.

Key Words * bone screw * lumbosacral fusion * metastasis * pedicle screw * spondylectomy * subluxation * tumor * vertebral body

Various techniques have been used to treat metastatic disease of the vertebral column. The extent of tumor resection ranges from a laminectomy, which provides decompression, to an extensive 
spondylectomy, in which the entire involved vertebral body is resected.[1,4,9-18] A concomitant stabilization procedure is needed to provide adequate fixation to facilitate fusion. Posterior, anterior, and combined approaches in which instrumentation is used have been performed to achieve these goals.[1,3-6,8-10,14,17,18] We present a reconstructive grafting technique for the treatment of a pathological entity affecting the L-5 vertebral body. A complete spondylectomy was performed in two stages: posterior decompression, placement of instrumentation, and fusion were followed by an anterior decompression, placement of instrumentation, and fusion.

\section{CASE REPORT}

History and Presentation. This 40-year-old woman presented with intraductal breast carcinoma involving the right breast. She underwent a lumpectomy and dissection of the lymph node, which demonstrated several positive lymph nodes but no systemic metastasis. She underwent chemotherapy and radiotherapy and remained asymptomatic for several months. She developed low-back pain that progressively worsened during the next 2 months, when she began to experience radicular pain in the right L-5 distribution. Metastasis to the L-5 vertebral body suggested by findings on a bone scan was confirmed by magnetic resonance imaging (Fig. 1), which revealed metastatic involvement of the L-5 vertebral body with a pathological fracture, compression of the thecal sac, and retropulsion of bone into the right L-5 neural foramen.

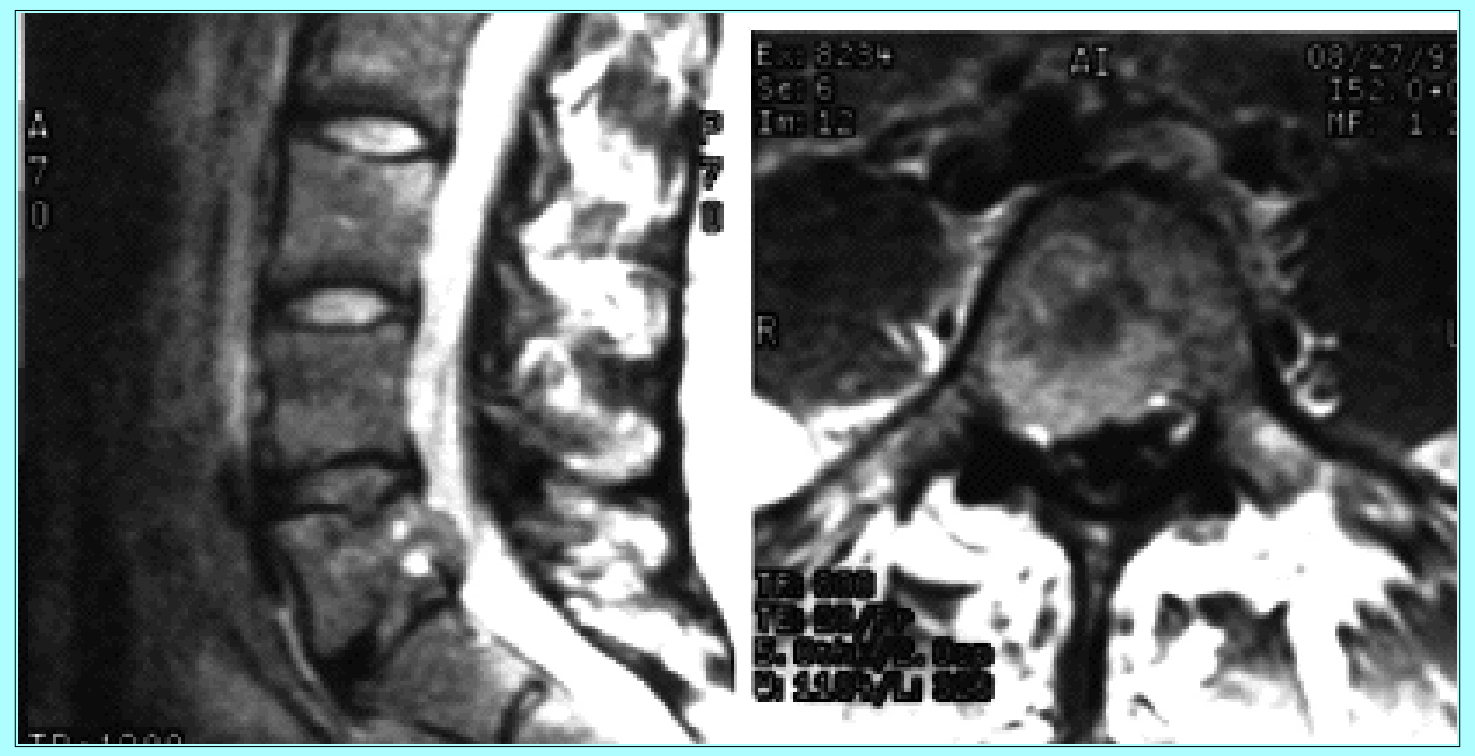

Fig. 1. Sagittal (left) and axial (right) contrast-enhanced magnetic resonance images in a 40-year-old woman who presented with low-back pain and right-sided L-5 radiculopathy. A destructive, heterogeneously enhancing lesion is seen in the L-5 body and pedicles. The ventral thecal sac and right L-5 nerve root are compressed.

The patient graded her pain as a constant 7 to 10 on a scale of 1 to 10 (with 10 reflecting the most pain). The pain worsened with activity and was relieved with recumbency. The distribution of discomfort was $65 \%$ back pain and $35 \%$ radicular pain. She also developed numbness and weakness of the right foot. She denied bowel or bladder dysfunction. She underwent radiation therapy of the lumbar spine but no relief of pain, numbness, or weakness was obtained.

Physical Examination. Her breast scar had healed well, and there were no palpable masses. Neurological examination revealed weakness of the extensor peroneus longus and anterior tibialis muscles, graded as $4 / 5$ on the right side; otherwise, her motor examination was $5 / 5$ in the left lower 
extremity and both upper extremities. Deep tendon reflexes were 1+ and symmetrical in the biceps, triceps, and brachioradialis muscles. Knee and ankle jerk reflexes were 2+ and 1+, respectively. Plantar reflexes were flexor. No spasticity or clonus was demonstrated. Sensory examination revealed intact light touch and pinprick sensation in both upper and lower extremities.

Operation. The patient underwent a two-stage approach after induction of anesthesia. In the first procedure, performed via the posterior approach, the L-5 lamina, bilateral facets, pedicles, and the posterior third of the vertebral body were removed. Texas Scottish Rite Hospital pedicle instrumentation was placed from L-4 to S-1. The L4--S1 transverse processes were fused using iliac crest autograft. The estimated blood loss for this procedure was $2000 \mathrm{ml}$, and the patient received $3000 \mathrm{ml}$ of crystalloid, $2 \mathrm{U}$ of packed red blood cells, and $500 \mathrm{ml}$ of plasma.

In the second stage of the operation, via an anterior approach, dissection and mobilization of the paraspinal autonomic plexus and great vessels were performed. The anterior two thirds of the L-5 vertebral body was completely removed using osteotomes and Kerrison rongeurs (Fig. 2 upper).

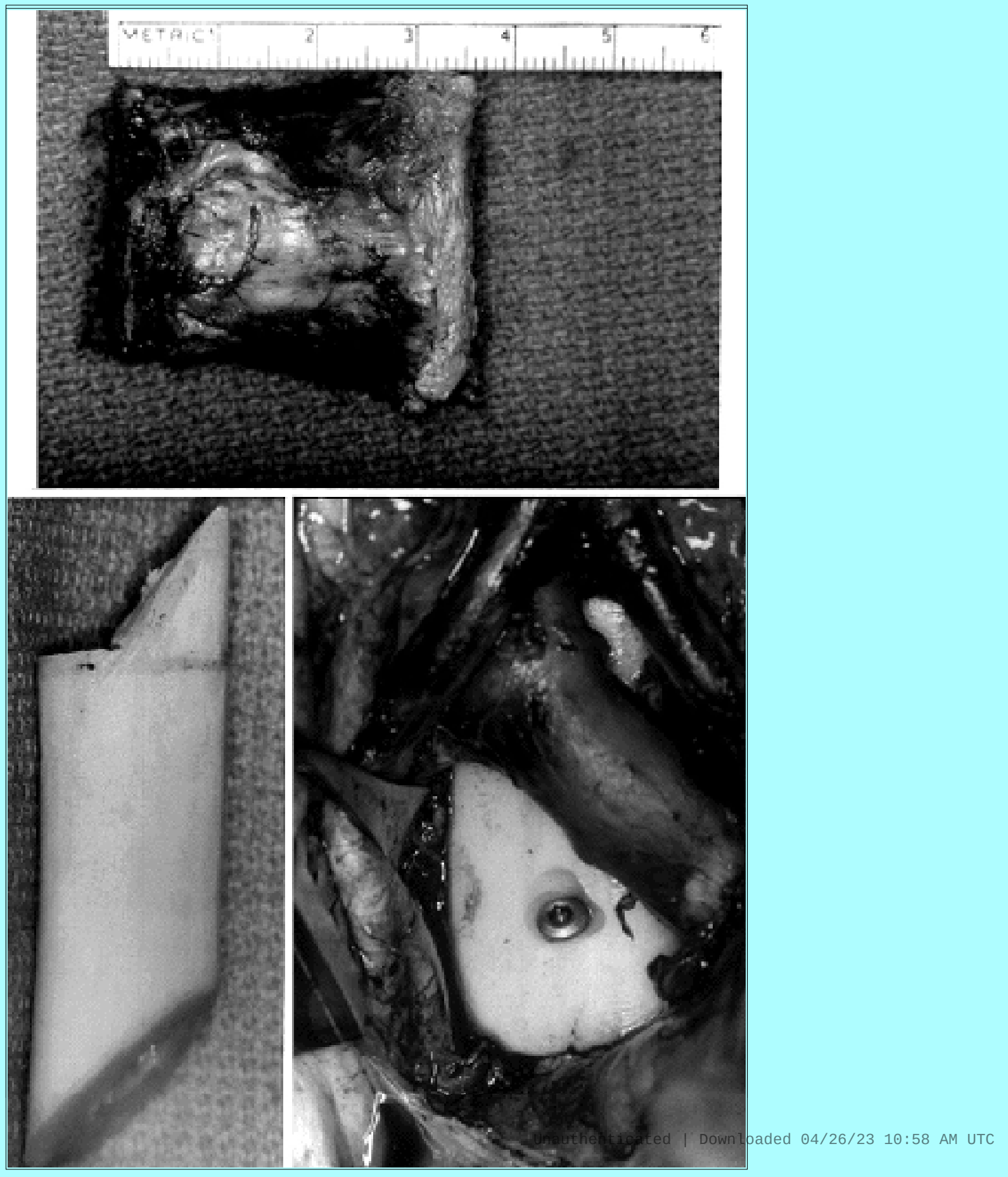


Fig. 2. Photographs. Upper: The ventral portion of the vertebral body was removed in one piece by using bone chisels. Lower left: An allograft bone strut was used for the L4--S1 interbody fusion. The spike fashioned on the superior aspect of the graft was impacted into the inferoposterior endplate of L-4. The inferior aspect of the graft was angled to coincide with the face of the superior endplate of the S-1 vertebral body. The cranial aspect of the graft was impacted into the L-4 vertebral body, and the caudal aspect was seated against the superior endplate of S-1 and secured using a bone screw. Lower right: Intraoperative view showing the anterior interbody fusion from L-4 to S-1 after the complete L-5 spondylectomy and L-5 and S-1 discectomies were performed. The inferior aspect of the graft is secured to the $\mathrm{S}-1$ body with a bone screw.

Because of the unique biomechanical properties of the lumbosacral junction, a novel anterior reconstruction was performed. A femoral allograft bone strut was fashioned (Fig. 2 lower left) with a rostral spike, which was driven into the inferoposterior aspect of the L-4 vertebral body to secure the upper portion of the graft. The inferior portion of the graft was cut to fit flush along the superior endplate of the S-1 vertebral body (Fig. 2 lower right). A 4-mm-diameter cancellous bone screw (Synthes, Paolia, PA) was placed through a drill hole made in the caudal surface of bone graft and inserted into the S-1 vertebral body to act as an inference screw or buttress to resist displacement of the graft. The head of the screw was recessed into the graft and did not make contact with the iliac vessels. The estimated blood loss during this portion of the procedure was $800 \mathrm{ml}$. The patient received $4500 \mathrm{ml}$ of crystalloid and $2 \mathrm{U}$ of packed red cells. There were no intraoperative or postoperative complications.

Postoperative Course. The patient's postoperative neurological examination revealed no new neurological deficits. Plain radiographs of the lumbosacral junction demonstrated good alignment of the allograft bone strut and proper placement of the anterior and posterior instrumentation (Fig. 3). At the time of discharge, the patient was wearing a thoracolumbosacral orthosis and was able to ambulate with the assistance of a walker. An outpatient course of external-beam radiation directed at L4--S2 was delivered in 10 fractions (total dose of $3000 \mathrm{cGy}$ ). At 19 month clinical follow-up examination, her neurological status was stable. She died 4 months later of metastatic disease. 


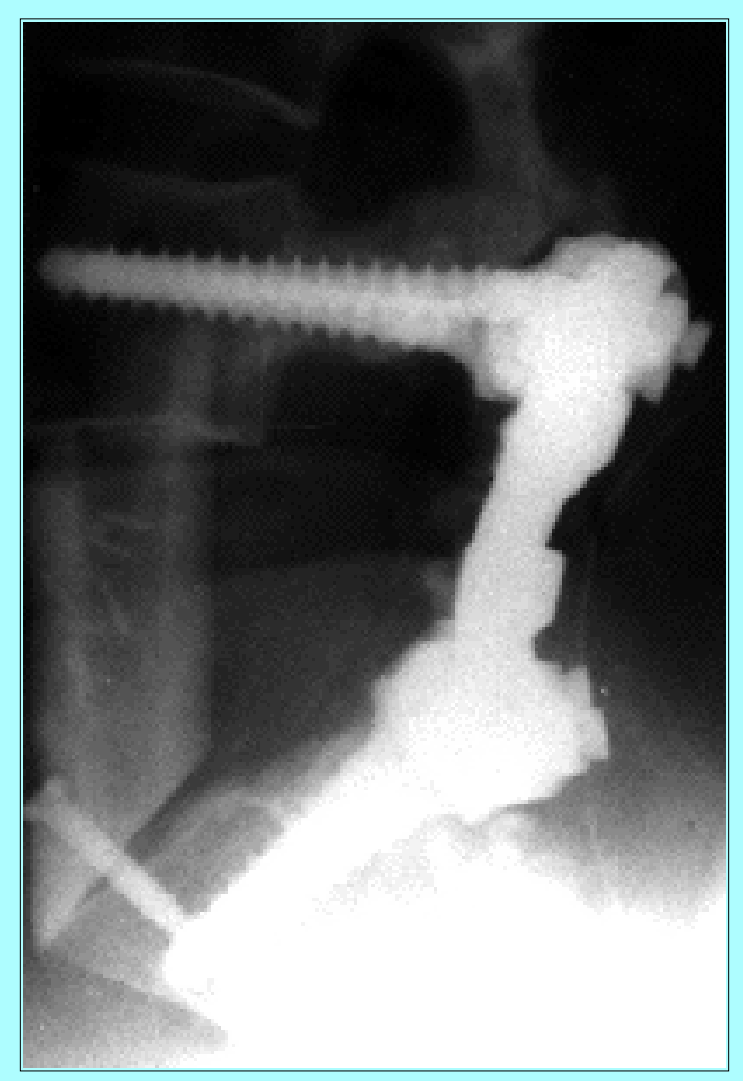

Fig. 3. Sagittal lumbar x-ray film obtained after complete L-5 spondylectomy. The posterior arch, pedicles, and posterior third of the vertebral body were removed during the first stage. After decompressive surgery, stabilization was achieved using pedicle screws extending from L-4 to S-1. During the second stage, the anterior vertebral body was removed and reconstructed using an allograft bone strut. The lumbosacral junction was stabilized, and a bone screw was placed aided by fluoroscopic guidance.

\section{DISCUSSION}

The definitive treatment of solitary metastases to the lumbar spine is controversial. Medical management includes steroid and radiation therapy.[14] A decompressive laminectomy[3,14,16] can facilitate decompression of the thecal sac. Further resection can include the facets and pedicles. Anterior decompressive procedure can be performed alone or in combination with a posterior approach for a spondylectomy.[1,4,6,8-11,13-18] A complete L1--3 spondylectomy is possible via a posterior approach but should be performed in two stages at L-4 and L-5.[10] In following this strategy, the iliac vessels are protected anteriorly and the limited retraction encountered posteriorly, due to the iliac wings, is overcome. Adequate literature exists to guide the surgeon in the resection, stabilization, and L1--4 fusion.[1,4,6,11,13-18] However, the published data on spinal reconstruction of the L-5 vertebral segment after complete spondylectomy is scant. $[3,10,17]$

The present technique facilitates complete local tumor removal and establishes immediate three-column stabilization. The middle and posterior columns are reconstructed with pedicle screws and intertransverse process fusion by using autograft materials. The anterior and middle columns are reconstituted with a precisely shaped tibial allograft, which is impacted into the body of L-4. The allograft lies flush against the superior endplate of S-1 and is secured with a bone screw into the body of $S-1$. The bone screw is drilled through the allograft to recess the screw to avoid making contact with the iliac arteries, thereby precluding the need of other anterior instrumentation in this region.[5,6,9-12] 


\section{Biomechanical Properties of the Lumbosacral Junction}

Biomechanically, the lumbosacral junction differs from other levels of the lumbar spine. Familiarity with these differences is paramount to understanding the compressive and shear loads that different forms of spinal reconstruction systems must resist after complete spondylectomy. Pedicle screws and rods are effective in preventing anterior subluxation at L5--S1 without loss of facet joint or disc integrity (unpublished data). Hence, the main modality of loading that the anterior bone graft would be required to resist is compression, which would be expected to occur during normal upright posture or flexion.

The geometry of the endplate bone-graft interface dictates how compression is transferred. In the case we present here, the rostral end of the graft was placed approximately perpendicular to the upright axis of the body because only a small amount of horizontal shear is expected. The caudal end of the graft was angled approximately $43^{\circ}$ from horizontal line, estimated from a lateral radiograph. A shear force along the interface of the graft and bone of $475 \mathrm{~N}$ would be expected.[2,7,19] At the caudal end of the graft, we placed a screw across a portion of the graft angled inferiorly into the sacrum. This configuration allowed the screw to act as a buttress, resisting forces occurring approximately perpendicular to the screw instead of along its axis.

\section{CONCLUSIONS}

The results of this case demonstrate the efficacy of performing complete spondylectomy for the treatment of solitary metastatic disease to the vertebral column. In this novel fusion technique a posterior approach with pedicle screws is combined with an anterior approach in which an allograft bone graft is secured with a bone screw.

\section{Acknowledgments}

The authors thank Shelley A. Kick, Ph.D., senior editor, and the staff of the Neuroscience Publications office at Barrow Neurological Institute for their assistance in preparing this manuscript.

\section{References}

1. Fidler MW: Radical resection of vertebral body tumours. A surgical technique used in ten cases. J Bone Joint Surg (Br) 76:765-772, 1994

2. Gelb DE, Lenke LG, Bridwell KH, et al: An analysis of sagittal spinal alignment in 100 asymptomatic middle and older aged volunteers. Spine 20:1351-1358, 1995

3. Hansebout RR, Blomquist GA Jr: Acrylic spinal fusion. A 20-year clinical series and technical note. J Neurosurg 53:606-612, 1980

4. Harrington KD: Anterior cord decompression and spinal stabilization for patients with metastatic lesions of the spine. J Neurosurg 61:107-117, 1984

5. Kaplan SS, Wright NM, Yundt KD, et al: Adjacent fracture-dislocations of the lumbosacral spine: case report. Neurosurgery 44:1134-1137, 1999

6. Matsui H, Tatezaki S, Tsuji H: Ceramic vertebral body replacement for metastatic spine tumors. J Spinal Disord 7:248-254, 1994 
7. Panjabi MM, Goel V, Oxland T, et al: Human lumbar vertebrae: quantitative three-dimensional anatomy. Spine 17:299-306, 1992

8. Roy-Camille R, Saillant MG, Lapresle P: Treatment of malignant tumors of the spine with posterior instrumentation, in Sundaresan N, Schmidek HH, Schiller AL, et al (eds): Tumors of the Spine.

Diagnosis and Clinical Management. Philadelphia: WB Saunders, 1990, pp 473-487

9. Siegal T, Siegal T: Surgical intervention for neoplastic involvement of the lumbar spine, in Sundaresan N, Schmidek HH, Schiller AL, et al (eds): Tumors of the Spine. Diagnosis and Clinical Management. Philadelphia: WB Saunders, 1990, pp 380-390

10. Stener B: Total spondylectomy in chondrosarcoma arising from the seventh thoracic vertebra. J Bone Joint Surg (Br) 53:288-295, 1971

11. Stener B: Complete removal of vertebrae for extirpation of tumors. A 20-year experience. Clin Orthop 245:72-82, 1989

12. Stener B: Total spondylectomy for removal of a giant-cell tumor in the eleventh thoracic vertebra. Spine 2:197-201, 1977

13. Stener B, Johnsen OE: Complete removal of three vertebrae for giant-cell tumour. J Bone Joint Surg (Br) 53:278-287, 1971

14. Sundaresan N, DiGiacinto GV, Hughes JEO: Surgical treatment of spinal metastases. Clin Neurosurg 33:503-522, 1986

15. Sundaresan N, DiGiacinto GV, Krol G, et al: Complete spondylectomy for malignant tumors, in Sundaresan N, Schmidek HH, Schiller AL, et al (eds): Tumors of the Spine. Diagnosis and Clinical Management. Philadelphia: WB Saunders, 1990, pp 438-445

16. Sundaresan N, DiGiacinto GV, Krol G, et al: Spondylectomy for malignant tumors of the spine. J Clin Oncol 7:1485-1491, 1989

17. Sundaresan N, Galicich JH, Lane JM, et al: Treatment of neoplastic epidural cord compression by vertebral body resection and stabilization. J Neurosurg 63:676-684, 1985

18. Tomita K, Kawahara N, Baba H, et al: Total en bloc spondylectomy. A new surgical technique for primary malignant vertebral tumors. Spine 22:324-333, 1997

19. White AA III, Panjabi MM: Clinical Biomechanics of the Spine, ed 2. Philadelphia: JB Lippincott, 1990

Manuscript received August 4, 1999.

Accepted in final form November 11, 1999.

Address reprint requests to: Curtis A. Dickman, M.D., Neuroscience Publications, Barrow Neurological Institute, 350 West Thomas Road, Phoenix, AZ 85013--4496. email: neuropub@ mha.chw.edu. 